\title{
A Percepção de Estagiários em Diferentes IES do Brasil sobre a Supervisão
}

The Perception of Interns in Different Institutions of Higher Education of Brazil on Supervision

La Percepción de Becarios en Diferentes IES del Brasil sobre la Supervisión

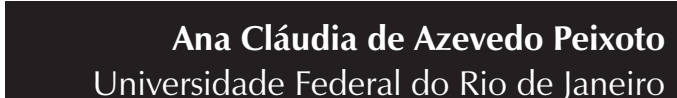

Edwiges Ferreira de Mattos Silvares Marina Monzani da Rocha Nancy Ramacciotti de Oliveira Monteiro Rodrigo Fernando Pereira Universidade de São Paulo

http://dx.doi.org/10.1590 / 1982 - 3703001482013

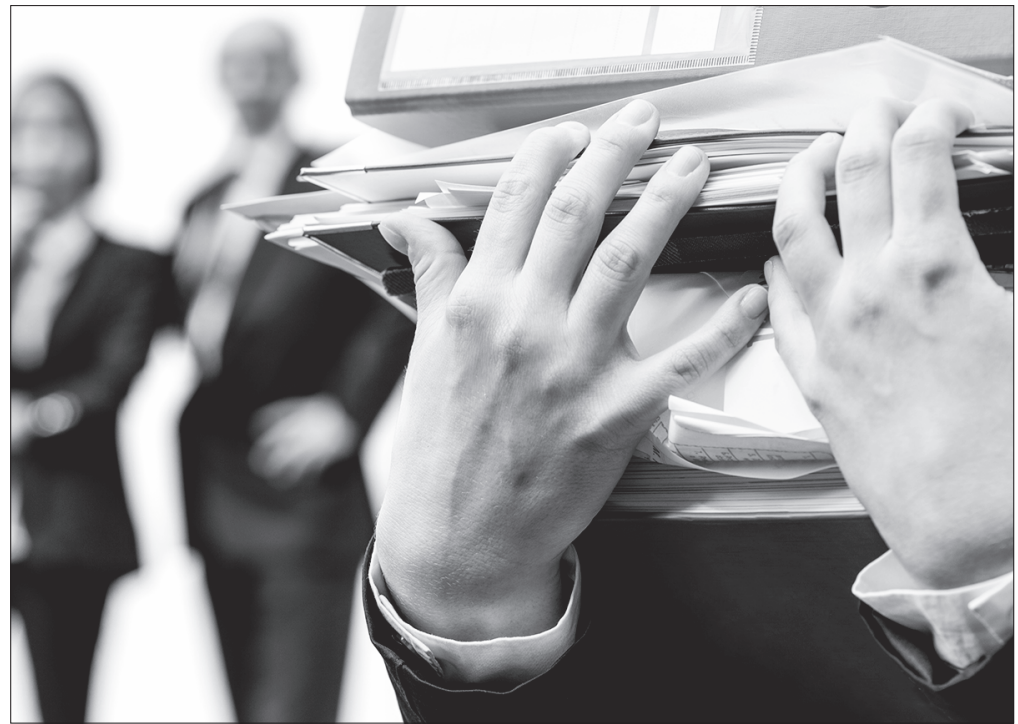


Resumo: Neste artigo, são apresentados os resultados referentes à análise qualitativa da percepção de estudantes de graduação em Psicologia envolvidos em algum tipo de estágio supervisionado. Um total de 312 alunos-estagiários dos 21 estados brasileiros respondeu o questionário disponibilizado em versão on-line para todas as instituições de ensino do país que aceitaram participar da pesquisa. Foi utilizada como instrumento para coleta dos dados a "Escala sobre a experiência de supervisão na ótica de estagiários de Psicologia", adaptada para o português, que engloba 27 questões fechadas e sete questões abertas. Para análise do conteúdo das respostas abertas, utilizou-se o software Sphinx Léxica (versão 5.0). Como resultado tem-se que a avaliação das supervisões por parte dos estagiários é bastante favorável aos supervisores e indicam que eles frequentemente apresentam comportamentos que favorecem o aprendizado e o aprimoramento do estagiário, tais como, apoiar o desejo de aprender do estagiário. Discute-se a percepção que o estagiário possui da relação com e seu supervisor no espaço da formação e instigam-se situações-problema na interação entre ele e seu supervisor. Palavras-chave: Formação profissional. Supervisão. Apercepção. Desenvolvimento profissional.

Abstract: In this article, results are presented concerning the qualitative analysis of perception of undergraduate students in psychology involved in some sort of supervised internship on their experience of supervision. A total of 312 student-interns of the 21 Brazilian states answered the questionnaire available in an online version for all educational institutions in the country that have agreed to participate in the research. Was used as an instrument for data collection the "scale on the optical supervision experience of interns in Psychology", adapted to Portuguese, including 27 closed questions and seven open questions. For analyzing the content of the open answers, we used the Sphinx Lexical software (version 5.0). As a result, we have that the evaluation of supervision on behalf of the trainees is quite favorable to supervisors and indicate that they often exhibit behaviors that promote learning and the improvement of interns, such as supporting the intern's desire to learn. It discusses the perception that the trainee has on the relationship with his supervisor in the area of training and instigate problem situations in the interaction between him and his supervisor.

Keywords: Professional education. Training. Aperception. Professional development

Resumen: En este artículo, son presentados los resultados referentes al análisis cualitativo de la percepción de estudiantes de graduación en Psicología involucrados en algún tipo de contrato supervisado de prácticas sobre la experiencia de la supervisión. Un total de 312 alumnos becarios de los 21 estados brasileños respondió al cuestionario proporcionado en versión online para todas las instituciones de enseñanza del país que aceptaron participar en la pesquisa. Fue utilizada como instrumento para colecta de los datos la "Escala sobre la experiencia de supervisión en la óptica de becarios de Psicología", adaptada para el portugués, que engloba 27 cuestiones cerradas y siete cuestiones abiertas. Para análisis del contenido de las respuestas abiertas, fue utilizado el software Sphinx Léxica (versión 5.0). Como resultado tenemos que la evaluación de las supervisiones por parte de los becarios es bastante favorable a los supervisores e indican que ellos frecuentemente presentan comportamientos que favorecen el aprendizaje y el perfeccionamiento del becario, tales como, apoyar el deseo de aprender del becario. Se discute la percepción que el becario posee de la relación con su supervisor en el espacio de la formación y se instigan situaciones problemáticas en la interacción entre él y su supervisor.

Palabras clave: Formación profesionale. Supervisión. Apercepción. Desarrollo profesional 
Em 2012, a regulamentação da profissão de psicólogo no Brasil completou cinquenta anos. Muitos congressos, publicações e discussões voltaram seus olhares para uma análise da história e o desenvolvimento alcançado pela Psicologia, que, nas duas últimas décadas, registrou expansão para diversos campos de atuação, locais e regiões do Brasil (Macedo \& Dimenstein, 2006). Apesar da Psicologia ter evoluído em muitos aspectos, ainda existem pontos nevrálgicos que continuam se interpondo entre o passado e o presente. Um deles trata da divisão entre os aspectos práticos, científicos, controláveis, experimentais e a teoria, com suas nuances subjetivas, parciais e idiossincráticas. A formação em Psicologia encontra-se atravessada por forças e, por isso, deve ser pensada e repensada (Nórte, Macieira, \& Rodrigues, 2010).

O contingente de psicólogos no Brasil é um dos maiores do mundo, já que, atualmente, existem mais de 250 mil profissionais formados e cerca de 131.500 estudantes, espalhados por mais 480 cursos de Psicologia. Atuando na formação desses alunos, existem em torno de 10 mil professores (Yamamoto, 2012). Nesse contingente de 10 mil profissionais que atuam na formação, encontram-se aqueles que estão conectados diretamente com a prática, os chamados supervisores de estágio básico e específico.

O estágio é uma atividade curricular obrigatória para a formação em Psicologia e se constitui em experiência acadêmico-profissional orientada para a competência técnico-científica. As atividades que circunscrevem os estágios têm como orientação possibilitar o questionamento curricular e, principalmente, relacionar teorias e práticas desenvolvidas ao longo das atividades curriculares.

O estágio supervisionado é uma modalidade obrigatória do curso de Psicologia e, conforme as novas Diretrizes Curriculares Nacionais para os cursos de graduação em Psicologia Resolução no 8, de 7 de maio de 2004, ele deve ocorrer em dois módulos: básico e es- pecífico. Como alguns de seus objetivos, o estágio busca integrar conhecimentos teórico-práticos por meio da pesquisa em diversas áreas da Psicologia e possibilitar ao aluno a reflexão ético-profissional. Já o estágio específico busca a coerência e continuidade no que se passa em sala de aula e nas atividades desenvolvidas. Espera-se que a prática do aluno propicie condições para a passagem do papel de estudante para o de profissional, o favorecimento com a integração no mercado de trabalho, a participação dos alunos em atividades científicas e comunitárias e a escolha e aplicação dos diversos saberes nos diversos campos de atuação psicológica.

Caracteriza-se como papel do aluno-estagiário em Psicologia a busca por um processo de singularização que irá possibilitar o desenvolvimento de suas próprias referências prático-teóricas. Essa construção possibilita ao aluno um senso de autonomia, tão importante na apropriação de sua identidade dentro do campo psi.

O corpo docente que participa do processo de formação precisa oferecer, em ambiente profissional, as condições necessárias aos alunos do curso de graduação para que seja possível o aprendizado de competências próprias da atividade. Os professores supervisores devem auxiliar por meio de pesquisas, relatos, discussões de casos, romper com a fronteira que demarca os diversos campos da Psicologia e fomentar as diferenças, atitude esta que propicia a construção da subjetividade e possibilidades de cada um. Os cursos de graduação desempenham um papel fundamental na determinação de modelos de atuação, mas, sem dúvida, é a supervisão considerada o elemento central no processo de aprendizagem, prática e aprimoramento da identidade do psicólogo.

Em uma pesquisa com alunos ingressantes e concluintes em todo o Brasil realizada por Souza, Bastos, \& Barbosa (2011), descobriuse que a Instituição de Ensino Superior (IES) contribui para a formação específica do psicólogo, mas não potencializa habilidades 
gerais imprescindíveis para o exercício profissional, como, por exemplo, analisar, sintetizar, criticar, deduzir, trabalhar em equipe ou administrar conflitos, sendo que tais habilidades que o estudante traz do ensino médio são pouco desenvolvidas no ensino superior. Nessa mesma pesquisa, os resultados do Exame $\mathrm{Na}$ cional de Desempenho de Estudantes (Enade) de 2006 apontam a necessidade de qualificação dos professores para todos os eixos da formação na graduação, assim como a necessidade de desenvolver novas estratégias de ensino que consigam recuperar a noção de competências e habilidades.

O espaço da formação é múltiplo, é onde saberes são constituídos e reproduzidos no intuito de melhor cartografar essa realidade. A intenção deste trabalho foi a de tentar uma aproximação do cotidiano da formação recolhendo falas de alunos quanto ao processo da supervisão. Essas questões solicitavam exemplos de situações concretas a respeito da supervisão, do supervisor e/ou do atendimento ocorrido no estágio supervisionado.

Os objetivos deste artigo são vários, entre eles estão: relatar e discutir aspectos qualitativos da percepção de alunos-estagiários de diferentes serviços-escolas ou serviços de Psicologia aplicada, no território do Brasil, quanto à relação entre eles e seus supervisores no espaço da formação; avaliar a atuação de seus supervisores diante de situaçõesproblema; avaliar os sentimentos que a situação de supervisão desperta no aluno-estagiário; averiguar as dificuldades encontradas no processo de supervisão, bem como os procedimentos práticos utilizados.

Nosso intuito é o de colocar em análise os paradigmas atuais sobre a realidade da supervisão em Psicologia, visto que não existe uma única forma para exercer essa atividade. Buscou-se refletir sobre como se agencia o espaço da formação de aluno em Psicologia, no intuito de romper com a lógica racionalista presente no pensamento ocidental, a qual evoca o profissional e a profissão do psicólogo como detentores de domínio do saber, co- locando-o em um lugar de total segurança e inquestionabilidade. Sabe-se pouco sobre o assunto e nada tem sido feito para ampliarmos os horizontes dessa situação. $\mathrm{O}$ acesso do supervisor aos avanços da ciência da supervisão é limitado, fazendo com que sua atuação ocorra baseada no bom senso, intuição ou a partir de sua própria referência teórica (Campos, 1998).

\section{Método}

\section{Amostra}

Participaram dessa pesquisa 312 alunos de cursos de Psicologia do Brasil, sendo 262 mulheres (84\%) e 50 (16\%) homens, indicando a forte presença feminina na profissão, em consonância com dados de outros estudos (Souza et al., 2011). A amostra foi composta por estudantes de graduação que estavam envolvidos em algum tipo de estágio supervisionado e englobou todas as regiões do país, sendo 19,4\% da região Centro-Oeste, 9,2\% da Nordeste, $6,7 \%$ da Norte, $42,4 \%$ da Sudeste e $22,3 \%$ da Sul. A média de idade foi 25,7 anos, com idade mínima de 18 anos e máxima de 61 anos.

\section{Instrumento}

Foi utilizada como instrumento para coleta dos dados a "Escala sobre a experiência de supervisão na ótica de estagiários de Psicologia", adaptada para o português a partir de um inventário desenvolvido por Nigan, Cameron, e Leverette (1997), que inclui 27 questões para os estagiários avaliarem seus supervisores, utilizando uma escala tipo Likert com cinco opções de respostas (nunca $=1$; raramente $=2 ; 50 \%=3$; frequentemente $=4$ e sempre $=5$ ) e sete questões abertas para análise da percepção do estudante quanto à atuação do seu supervisor. Para análise das respostas às questões abertas, foco do presente trabalho, foi utilizado o sistema Sphinx de pesquisa. 


\section{Procedimentos}

Os resultados analisados neste trabalho referem-se ao recorte de uma pesquisa maior, realizada pelo Grupo de Trabalho (GT) "Atendimento psicológico em clínicasescola" da Associação Nacional de Pesquisa e Pós-graduação em Psicologia (Anpepp), o qual contou com apoio do Conselho Nacional de Desenvolvimento Científico e Tecnológico (CNPq) e da Associação Brasileira do Ensino da Psicologia (Abep). A pesquisa foi intitulada Serviços-escola de Psicologia no Brasil e foi aprovada pelo Comitê de Ética em Pesquisa da Universidade de São Paulo - USP (Parecer Of. 042/08CEPHIP/08/07/2008). Uma vez obtido o parecer de aprovação, coordenadores de todos os cursos de Psicologia do país foram convidados para participação no estudo. Os que aceitaram, receberam orientações padronizadas para encaminhamento do convite para três segmentos: 1) os gestores dos serviços-escola do curso; 2) supervisores; e 3) estagiários supervisionados. A proposta incluía o acesso on-line a questionários direcionados a cada um desses segmentos. Um programa de informática desenvolvido especialmente para o estudo permitiu proteger os dados, de forma que o acesso a cada formulário fosse feito apenas pelo respondente, via seu número de Cadastro de Pessoa Física (CPF) e, posteriormente, sem identificação do respondente, pelos pesquisadores.

No presente estudo, trabalhamos com os dados obtidos com o terceiro segmento foco da pesquisa: os estagiários supervisionados. Eles responderam o questionário "Escala sobre a experiência de supervisão na ótica de estagiários de Psicologia" por meio da internet, em um sítio desenvolvido para a realização dessa pesquisa. Cada usuário era identificado pelo seu Cadastro de Pessoa Física (CPF) e recebia uma senha que permitia que a participação fosse interrompida e continuada em outro momento. Antes do início da resposta, era apresentado um termo de consentimento e o assentimento dele era condição para participação.
Sete eram as questões do tipo aberto para as quais o respondente poderia desenvolver suas respostas, cuja análise é o foco do presente estudo. Essas questões solicitavam exemplos de situações concretas a respeito da supervisão, do supervisor e/ou do atendimento ocorrido no estágio supervisionado. Tais questões tiveram uma quantidade muito menor de respondentes em comparação às questões fechadas da escala tipo Likert: cerca de metade dos respondentes atendeu às solicitações das sete questões abertas de forma dissertativa on-line.

\section{Resultados e Discussão}

\section{Análise Qualitativa das Questões Abertas}

Abaixo, apresentam-se tendências obtidas nessas respostas às sete questões abertas do questionário, organizadas por questão.

Questão 6.1 - Essa questão pedia que o entrevistado sugerisse um exemplo de situações em que se sentia desaprovado pelo supervisor, desaprovação essa que poderia ter diferentes graus indicados pela questão fechada imediatamente anterior (Questão 6). Nos exemplos fornecidos, vários respondentes (18\%) negavam a desaprovação do supervisor, $13 \%$ relataram discordância entre supervisor e estagiário e poucos referiram a desaprovação do supervisor como parte inerente do processo de formação na supervisão. Os alunos que deram exemplos de desaprovação, em sua maioria, indicaram que a desaprovação ocorrera por falhas próprias (do supervisionando), como erros técnicos (13\%), estudo e experiência insuficiente $(11 \%)$, não cumprimento de tarefas/prazos (7\%) e inadequação de conduta na supervisão (4\%). Entretanto, também ocorreram exemplos relacionados a conflitos de identificação teórica/técnica (supervisionando/supervisor), além de críticas negativas diretas ao supervisor (com citação de intolerância, falta de respeito, falta de entendimento e de diálogo). 
Corroborando o relato acima, o sistema Sphinx apresentou maior concordância lexical com a palavra "não", sendo que das 21 observações com a palavra não, oito vezes ela se relaciona com a atuação negativa do próprio estagiário, em detrimento de uma falha do supervisor (seis vezes). A segunda maior concordância apresentada foi com as palavras "desaprovado" e "sempre" (quatro vezes). Esta última remete à ideia de sempre o supervisor apoiar situações de aprendizagem pelo aluno e, por isso, este não se sente desaprovado. $\mathrm{O}$ que se pretende alcançar no período final de estágio é que o aluno-estagiário esteja confiante para lidar com as angústias e incertezas inerentes de sua iniciação como profissional e tenha construído as bases de sua identidade profissional. A identidade construída será o resultado da síntese dos fatores, tais como: informações adquiridas, conhecimento técnico da área e de suas habilidades pessoais e relação entre supervisor e supervisionando. Sobre este item, a relação entre supervisor e aluno possibilita as últimas "amarras" para o estabelecimento de uma identidade profissional por parte do alunoestagiário. Segundo Neto (2006), a dificuldade em estabelecermos uma identidade na profissão da Psicologia está entre as sete pragas (dificuldades) desde o surgimento dos primeiros cursos no Brasil, além do descompasso entre o que está sendo ensinado e aprendido. Ao longo do curso de Psicologia, o aluno tem contato com diferentes estilos pessoais de professores supervisores, muitas vezes dentro das mesmas áreas de atuação. Os estagiários precisam aprender um método e definir um estilo pessoal, para isso, necessitarão de orientação e acompanhamento para guiar seus primeiros passos no amadurecimento profissional e pessoal. As experiências de estágio, as supervisões e os debates presentes em sala de aula podem ser espaços privilegiados para a experimentação e a construção de uma Psicologia que não se separa da política, nem da vida (Nascimento, Manzini, \& Bocco, 2006). Segundo Freitas (2008), existem três maneiras distintas de se avaliar o desempenho do aluno: o modo como o próprio aluno se avalia, o modo como o seu supervisor o avalia e a avaliação do cliente. Mas a forma primordial de avaliação ocorre por parte do supervisor, pois é ele quem estabelece as metas a serem cumpridas e o desempenho a ser alcançado.

Questão 25.1 - Essa questão indagava o motivo de uma possível falta de confiança do supervisionando no supervisor, por aquele ter omitido, na supervisão, fatos ocorridos no atendimento, como ficava indicado na questão fechada imediatamente anterior (Questão 25). Os motivos indicados foram: (33\%) relacionados ao medo de críticas feitas pelo supervisor e, em alguns casos, do grupo de supervisão, com utilização de termos como vergonha e insegurança. Houve também indicativos (9\%) de que o motivo para a omissão estava localizado em falhas pessoais do supervisor (que "não entenderia", "não daria importância", ou "não aceitava sugestão"). Algumas respostas (6\%) apresentavam desculpas diante de omissões ocorridas, como por esquecimento ou postergação do relato (falaria depois, decidiu esperar) e 12\% perceberam que havia errado no processo de intervenção do caso atendido.

Ocorreu novamente uma concordância da palavra "não", com sete ocorrências, sendo três observações negativas quanto à atuação do supervisor e quatro observações que negavam a falta de confiança. Na disciplina de estágio, de acordo com Távora (2002), o estagiário faz a escolha de seu supervisor ou área em que deseja atuar seguindo alguns critérios: área de atuação preferida, abordagem teórica de maior identificação, simpatia e/ou afinidade com o supervisor e disponibilidade deste. De acordo com a mesma autora, os vínculos estabelecidos entre estagiário e supervisor facilitam a elaboração das escoIhas feitas pelo estudante durante o processo de treinamento.

Questão 28 - Essa questão solicitava o relato de alguma lembrança de ato do supervisionando diante de um impasse no tratamento e quando nada de novo ocorrera na supervisão. As tendências de respostas incluíram, 
em sua maioria, pedidos de ajuda ao supervisor e discussões na supervisão (32\%), apesar do enunciado dessa mesma questão expressar "nada novo está acontecendo na supervisão". Houve também indicativos de procura de apoio bibliográfico (16\%), mudança da técnica ou da estratégia utilizada (10\%), aprofundamento de reflexões e retomada de apontamentos sobre o caso (7\%). Alguns indicaram que procuravam ajuda fora do processo de supervisão, incluindo a psicoterapia pessoal.

$\mathrm{Na}$ análise lexical, observou-se novamente uma concordância com a palavra "não", que apresentou 28 ocorrências. Ao ser analisada a conotação relacionada à palavra "não", observou-se que se referia, preferencialmente, ao fato de não ter acontecido nenhum tipo de impasse. A segunda maior concordância ocorreu com a palavra "supervisão" e seus sinônimos (supervisões, supervisionados, supervisor...) e descobriu-se que os respondentes (alunos), posteriormente ao fato de negar o impasse, procuraram descrever atitudes que costumam ter diante das poucas possibilidades de impasse. Ficou evidente que a própria supervisão era, em si, o melhor e mais utilizado instrumento na resolução dos impasses. As expressões "falei com", "me dirijo", "conversei", "pedi ajuda", "dialoguei", "pedi orientação" foram as que mais ocorreram e, por isso, talvez exista a negação de impasses. O próprio relacionamento estabelecido entre supervisor e supervisionando, que ocorre por meio de diálogo, espelha-se na terceira palavra de maior ocorrência nesse item que foi "conversar / conversando" com sete ocorrências. Essas respostas evidenciam a correlação entre essas posições e as descrições feitas por Aguirre (2000a, 2000b), Lima (2009), Távora (2002) e Zaslavsky, Nunes, Eizirik (2003) sobre as atividades desenvolvidas nas aulas de supervisão, que constam de: propiciar a formação técnico-profissional; integrar a teoria e a prática por meio de vivência de experiência o mais próximo possível de situações reais; propiciar maior contato com a área escolhida; analisar textos e/ou artigos concernentes a área; levantar e estudar diferentes formas de procedimentos de intervenção; relatar casos em atendimentos; escrever as sessões por escrito e entregar para o supervisor; discutir casos já atendidos ou em atendimento; fazer dramatizações no intuito de facilitar o aprendizado, por exemplo, da função e papel do terapeuta; analisar cenas de filmes e discutir vídeos que sejam relevantes para a supervisão; analisar sessões que foram gravadas em atendimentos realizados pelos alunos-estagiários; preencher instrumentos de autoavaliação e autocorreção; realizar (o supervisor) técnicas utilizadas por ele; e corrigir intervenções feitas pelo supervisionando.

Questão 29 - Essa questão propunha uma indagação associada à questão anterior (Questão 28), mas agora relacionada ao ato do supervisor diante de um impasse no tratamento. As respostas dissertativas tenderam a afirmar que, diante de situações de impasse, $20 \%$ dos supervisores ajudavam com orientações técnicas, $16 \%$ relataram que o tratamento e as abordagens foram repensados, $15 \%$ sugeriram buscas na literatura, 14\% apoiaram o aluno na decisão e $11 \%$ trouxeram exemplos ou indicaram bibliografia. Apenas 3\% responderam que a atuação do supervisor havia sido pouco efetiva. Esses dados acima corroboram a visão de que diversas variáveis podem influenciar no desenvolvimento da supervisão, como aspectos do estilo ou habilidades do supervisor, da abordagem em que ela está inserida, do número de alunos em sala de aula, do tipo de relacionamento entre supervisor e supervisionando, das crenças que o supervisionando possui em relação ao estágio e ao supervisor. Pelos resultados apresentados, fica evidente que quase a totalidade da amostra avaliou de forma positiva a atuação do supervisor em relação às suas necessidades enquanto alunos.

Novamente a palavra "não" apresentou maior nível de ocorrências, que indicavam, quando analisadas, que nunca ocorreu um impasse ou que ainda não passaram por essa situação, representando 15 ocorrências. Seguida dessa palavra, a maior concordância se deu com a palavra "caso", em seis ocorrências. A palavra 
"caso" se reportou a atitudes positivas ou facilitadoras do supervisor diante das possibilidades de um impasse, ratificando as porcentagens no parágrafo acima. Outra palavra que também apresentou seis (6) ocorrências foi "eu", com conotação também positiva do supervisor relacionada ao desenvolvimento pessoal e atitudes do aluno em supervisão. As palavras "melhor", "novas" e "orientação" apareceram em quatro (4) ocorrências, indicando que o supervisor procurou a melhor maneira e novas formas para orientar a saída diante de um impasse. Espera-se que a atitude do supervisor seja a de estimular o supervisionando a desenvolver suas próprias habilidades como futuro profissional da área pleiteada e ajudar o aluno a perceber suas dificuldades no processo de habilitação para atuação naquela área do estágio. Dessa forma, acredita-se que o aluno possa se desenvolver de forma autônoma; servir como modelo de identificação para atuação do estagiário; apoiar o desejo e ambição do aluno em buscar mais informações sobre diversos temas inerentes à abordagem utilizada; estabelecer uma aliança com o aluno; e transmitir valores éticos e sociais relacionados à profissão. Segundo Aguirre (2000a), entre as funções do supervisor estão: orientar e dar respaldo aos alunos em tudo que se refere ao atendimento, inclusive quanto às dúvidas e receios que vão aparecendo, ainda antes de iniciar o contato com o cliente, no caso de atendimento clínico, durante o decorrer de todo o trabalho e mesmo após sua finalização; oferecer um modelo de trabalho, transmitir valores de respeito e compreensão ao ser humano, além das estratégias possíveis de atuação do psicólogo. O supervisor é responsável, inclusive, perante o Conselho Regional de Psicologia, órgão fiscalizador da profissão.

Questão 30 - Essa questão solicitava um exemplo de uma situação de interação entre terapeuta (supervisionando) e cliente em que trouxera um impasse na supervisão e nenhuma ocorrência de novo aprendizado. A maioria das respostas $(60 \%)$ a essa questão negou a ocorrência de impasse na supervisão, com negativas para exemplos e afirmações, re- forçando a negação de tal problema. Entretanto, quando citados, os exemplos desse tipo de impasse tenderam a apontar críticas ao supervisor (pessoais e de incompetência técnica e teórica), com discordância sobre o encaminhamento do caso e indicativos de ações autônomas do supervisionando sem conhecimento do supervisor (omissões), além de referências a problemas institucionais motivadores de impasses nos atendimentos de casos (15\%); não resposta do paciente ao tratamento $(5 \%)$; problemas entre estagiário e supervisor (4\%); e o supervisor não soube como agir (3\%). Sant'Ana (1999) discorre muito bem em seu artigo sobre a importância de que o aluno-terapeuta precisa em captar, perceber e compreender as dificuldades do cliente para, se possível, saná-las. O estágio não se restringe a apenas aplicar as capacidades técnicas, mas se trata da possibilidade que o aluno tem de desenvolver habilidades interpessoais, que favorecerão melhores resultados no processo terapêutico.

Essa questão apresentou o maior número de ocorrência de concordância, 42, que se deu com a palavra "não". O significado da palavra "não" está relacionado 28 vezes, dentre as 42, ao fato dessa situação nunca ter ocorrido ou não estarem lembrando do ocorrido. As palavras que seguiram em concordância foram "pacientes" (9) e "ocorrências" (7) e relacionam as ideias de tal fato não ter ocorrido com seus pacientes, o que justifica os $60 \%$ relatados acima.

Questão 32 - Tal questão solicitava exemplo de situação do estágio com problemas de difícil solução. Verificou-se que 33\% relataram que não ocorreram. Os exemplos descritos ficaram mais centrados nas peculiaridades dos casos atendidos, sendo que $11 \%$ dos estagiários relataram que o paciente não colaborava; $9 \%$ relataram problemas financeiros e institucionais; $8 \%$ dificuldades pessoais do supervisionando para lidar com seus casos; $4 \%$ relataram problemas de evasão; $3 \%$ proximidade com o paciente e $2 \%$ falta de resposta ao tratamento. Além disso, ocorreram algumas citações de problemas na 
própria supervisão, como falta de tempo para colocar o caso e dificuldades pessoais do supervisor. Interessante notar que a maior parte dos problemas listados se situava fora do controle dos estagiários, indicando, talvez, uma possível supremacia da prática terapêutica em relação a outras formas de atuação.

Para corroborar a estatística de que 33\% alunos relataram não terem vivenciado uma situação de difícil solução, a palavra de maior concordância nesse item foi o "não", significando a negação para a questão perguntada, com 35 ocorrências. Destas, 20 se referiram a problemas relacionados com atitudes do próprio paciente e suas expectativas em relação à terapia. A segunda maior concordância $(n=19)$ apresentou-se com a palavra "paciente", sendo que 11 descrições se referiam às dificuldades inerentes à vida, postura ou situação socioeconômica do paciente, que serviam como obstáculo ou se enquadraram como fatos de difícil solução.

Questão 33 - Essa última questão do instrumento pedia um exemplo de situação do estágio que fora gratificante e bem sucedida. A grande maioria das respostas (50\%) a essa questão apontava um entendimento de consequências positivas do atendimento (progressos no caso atendido), demonstrado por vezes pela aprovação do supervisor ao supervisionando e por feedbacks positivos de pacientes e seus familiares. Exemplos de situações gratificantes também incluíam relatos de evolução e superação pessoal de dificuldades e percepção do desenvolvimento de habilidades (do supervisionado): $10 \%$ relataram que a supervisão funcionou, $6 \%$ obtiveram o agradecimento e reconhecimento da melhora, $6 \%$ observaram uma evolução pessoal, $3 \%$ reportaram elogio do supervisor, $3 \%$ apontavam feedback positivo do supervisor e $1,9 \%$ relatou alta do paciente.

Foram descritas 39 ocorrências com a palavra "paciente". Esta se relacionou com a avaliação positiva do estagiário em relação ao seu trabalho terapêutico. 33 dessas ocorrências se reportaram a melhoras por parte do paciente com feedback para os estagiários ou por meio da fala e/ou mudança positiva diante dos fatos vivenciados. A palavra "melhor" (9) e "respostas" (6) obtiveram as concordâncias seguintes, comprovando que os pacientes obtiveram as melhores respostas e essa situação era considerada gratificante e bem sucedida.

Falar da formação em Psicologia hoje significa fazer um recorte em um plano constituído por múltiplos vetores. A questão da formação em Psicologia é um processo nada linear. Embora, aparentemente, ordenado -: início de graduação, escolha de uma teoria, início do(s) estágio(s), intervenção e conclusão do curso -, o trânsito interno na Psicologia tem uma vasta dimensão de posicionamentos teóricos, que podem gerar, nesse processo de construção da identidade psicológica por parte do aluno, uma tensão e dificuldades que são inerentes a esse processo de escolha. A formação profissional na Psicologia deve ser entendida como um importante meio de construção subjetiva sobre o que é ser psicólogo e como deve ser a sua prática (Yukimitsu, 1999). O resultado dessa construção será subsidiado, em grande parte, por meio de procedimento teóricoprático que professores supervisores utilizam em suas aulas e supervisões, bem como, por meio de relatos de pesquisas como este.

\section{Conclusão}

A supervisão pode ser definida como um processo de ensino-aprendizagem por meio de diversas abordagens para atuação em uma área da Psicologia, realizado por um supervisor e seu supervisionando (Zaslavsky et al., 2003). Pelas respostas abertas analisadas, percebese que nesse processo o supervisor é supervalorizado e seu papel é visto como irrepreensível, sem necessidade de reparos, pois poucos foram os estagiários que indicaram ter vivenciado algumas das situações de impasses colocadas, e as soluções encontradas para as situações de impasse reconhecidas são quase sempre vistas como raras. 
Sabe-se que, no processo de ensino-aprendizagem, vários estímulos competem entre si para o estabelecimento do resultado final. Segundo Campos (1995), diversas variáveis podem influenciar o andamento da supervisão, como os aspectos da relação supervisor-supervisionado; o número de alunos por grupo; o estilo do supervisor, considerando que cada profissional adota um modelo único, de acordo com seus valores, crenças e habilidades; e a abordagem teórica que cada profissional possui. Nenhum desses aspectos, entretanto, foi citado como geradores de conflito ou impasse nas respostas qualitativas analisadas.

A respeito dos procedimentos desenvolvidos e utilizados para a avaliação do processo de supervisão, Rodrigues (2007) afirma que não há muita clareza, objetividade e uniformidade quanto a esses critérios de avaliação e faltam instrumentos para avaliar os desempenhos e atividades dos estagiários em quase todas as áreas. Sem contar a falta de instrumentos que mensurem os padrões de profissionalismo competente e ético, que tanto desejamos em nossa profissão. Por isso, avaliar e refletir a prática da supervisão em Psicologia, sob a ótica do aluno-estagiário foi um dos objetivos deste artigo. Nossa intenção foi problematizar o vetor supervisão na formação do psicólogo, tornando-o não apenas objeto de teorização e exercício, mas de um lugar que passa estreitamente pela aquisição de competências, mas também e, principalmente, pela conquista de certo ethos, uma atitude em relação às práticas nas quais se está inserida, que possibilita inventar novos modos de ser psicólogo.

Os resultados deste trabalho de pesquisa tratam de investigar os caminhos na formação da identidade-psicólogo, de certa forma fica evidente a relação dialógica existente nessa travessia que se acredita como caminho. A avaliação das supervisões por parte dos estagiários é bastante favorável aos supervisores. Os estagiários indicaram que os supervisores frequentemente apresentam comportamentos que favorecem o aprendizado e o aprimoramento do estagiário, tais como, apoiar o desejo de aprender do estagiário e respeitar este, corroborado pelo próprio resultado do trabalho do aluno com seu paciente. Espera-se que, por meio dos estágios supervisionados, garanta-se minimamente a constituição de ações formativas no eixo da prática profissional. Como resultado desses 50 anos de atuação da Psicologia, está claro que muito ainda precisa ser percorrido para o alcance do equilíbrio entre prática e teoria, também na apropriação da nossa identidade como psicólogos e professores dessa área, de nosso papel diante da sociedade e de nossa primeira clientela, que são os alunos-estagiários.

Seguramente este artigo não esgota a amplitude do tema proposto, mas, ao contrário, remete à troca de experiências e reflexões com nossos colegas envolvidos na formação de psicólogos, especificamente os envolvidos no processo de supervisão. Decorre disso, necessária ênfase em novas pesquisas e estudos sobre o ensino/aprendizagem, sobre a relação entre supervisores e estagiários, a respeito da criação de instrumentos que viabilizem a avaliação dos processos que envolvem a supervisão, bem como da atuação do supervisor e do próprio supervisionando. Nossa preocupação maior é com a formação do aluno que, em bem pouco tempo, estará lidando com vidas e re-produzindo saberes sobre a aplicabilidade da Psicologia 


\section{Ana Cláudia de Azevedo Peixoto}

Doutora em Psicologia pela Universidade Federal do Rio de Janeiro e Docente da Universidade Federal Rural do Rio de Janeiro - RJ. Brasil.

E-mail: claudiaapeixoto@gmail.com

\section{Edwiges Ferreira de Mattos Silvares}

Doutora em Psicologia Experimental pela Universidade de São Paulo e Docente da Universidade de São Paulo - SP. Brasil.

E-mail: efdmsilv@usp.br

\section{Marina Monzani da Rocha}

Doutora em Psicologia Clínica pela Universidade de São Paulo e Docente da Universidade Paulista - SP. Brasil.

E-mail: marinamonzani@gmail.com

\section{Nancy Ramacciotti de Oliveira Monteiro}

Pós-doutora em Psicologia Social pela Universidade de São Paulo e Docente da Universidade Federal de São Paulo - SP. Brasil.

E-mail: nancy.unifesp@gmail.com

\section{Rodrigo Fernando Pereira}

Doutor em Psicologia Clínica pela Universidade de São Paulo - SP. Brasil.

E-mail:rpereira@usp.br

Endereço para envio de correspondência:

BR 465 Km 07 Seropédica CEP: 23860-000. Rio de Janeiro, RJ. Brasil

Recebido 22/06/2013, Aprovado 28/07/2014. 


\section{Referências}

Aguirre, A. M. B. (2000a).A primeira experiência clínica do aluno: ansiedades e fantasias no atendimento e na supervisão. Psicologia: Teoria e Prática, 2(1), 3-31.

Aguirre, A. M. B. et al. (2000b). A formação da atitude clínica no estagiário Psicologia. Psicologia USP, 11(1). 49-62. doi: 10.1590/S0103-65642000000100004

Campos, L. F. L. (1995). Investigando a formação e atuação do supervisor de estágio em Psicologia Clínica. Estudos de Psicologia, Campinas, 12(3), 7-29.

Campos, L. F. L.. (1998). Supervisão em terapia cogntivo-comportamental. In Rangé, B., et al. Psicoterapia Comportamental e Cognitiva. Campinas, SP: Editorial Psy II.

Freitas, F. A. (2008). Diferentes perspectivas diante da conduta do estagiário em Psicologia no contexto clínico. Psicologia teoria e prática. São Paulo, 10(2). 31-48.

Lima, M. F. E. M. (2009). Estágio supervisionado em Psicologia Escolar: desmistificando o modelo clínico. Psicologia: Ciência e Profissão, 29(3). doi 10.1590/S1414-98932009000300016.

Macedo, J. P., \& Dimenstein, M. (2006). Expansão e interiorização da psicologia: reorganização dos saberes e poderes na atualidade. Psicologia: Ciência e Profissão, 31(2), 296-323. doi: http://dx.doi.org/10.1590/S1414-98932011000200008

Nascimento, M. L., Manzini, J. M., \& Bocco, F. (2006). Reinventando as práticas psi. Psicologia e Sociedade, 18(1), 15-20.doi 10.1590/S010271822006000100003.

Neto, S. P. (2006). Aonde vai a psicologia? Algumas considerações sobre o passado, o presente e o futuro da psicologia como ciência, profissão e ensino. Boletim Academia Paulista de Psicologia. São Paulo, 26(3) 45-52.

Nigan, T., Cameron, P. M., \& Leverette, J. S. (1997). Impasses in the supervisory process: A resident's perspective. American Journal of Psychoterapy, 51(2), 252-272.
Nórte, C. E., Macieira, R. M., \& Rodrigues, B.C. (2010). Da docilização à estética da existência: direitos humanos na formação em Psicologia. In C. E. Nórte, R. M. Macieira, \& L. L. Furtado, L.L. Formação: ética, política e subjetividades na psicologia. (pp. 58-67). Rio de Janeiro: Conselho Regional de Psicologia.

Rodrigues, H. B. C. (2007). Formação Psi: reforma psiquiátrica, atenção psicossocial, In J. C. Mourão. (Org.), Clínica e Política 2 (pp. 201-206). Rio de Janeiro: Abaquar

Sant'Ana, V. L. P. (1999). A formação do psicoterapeuta. Psicologia em Estudo, 4(1), 61-65.

Souza, M. P. R. Bastos, A. V., \& Barbosa, D. R. (2011, dez.). Formação básica e profissional do psicólogo: análise do desempenho dos estudantes no ENADE-2006. Avaliação. psicol., Itatiba, 10,(3), 295-312. Recuperado de http://p e p s i c. bvs a I u d. org/s c i e I o . php?script $=$ sci_arttext $\&$ pid $=$ S1677-04712011$000300005 \& \operatorname{lng}=$ pt\&nrm $=$ iso\&tlng $=$ pt

Yamamoto, H. O. (2012). 50 anos de profissão: responsabilidade social ou projeto ético- político? Psicologia: Ciência e Profissão, 32(1), 6-15. doi: 10.1590/S1414-98932012000500002

Távora, M. T. Um modelo de supervisão em psicologia na formação do estudante em psicologia: a experiência da UFC. (2002). Psicologia em Estudo. Maringá, 7(1), p. 121-130. doi: http://dx.doi.org/10.1590/S1413-73722002000100015.

Zaslavsky, J., Nunes. M. L. T, \& Eizirik. C. L. (2003). A supervisão psicanalítica: revisão e uma proposta de sistematização. Revista Psiquiatria do Rio Grande do Sul. Porto Alegre, 25(2). doi: http://dx.doi.org/10.1590/S0101-81082003000200006..

Yukimitsu, M. T. C. P. (1999). A supervisão na formação do psicólogo clínico. In Witter, C. (Org.), Ensino de Psicologia. (pp. 169-204). Campinas, SP: Alínea. (Coleção Psicotemas), 